\title{
A MODEL FOR LIFECYCLE COST CALCULATION BASED ON ASSET HEALTH INDEX
}

\author{
J. Serra ${ }^{1}$, A. de la Fuente ${ }^{2}, A$. Crespo $^{2 *}$, A. Sola, A. Guillén ${ }^{2}$, E. Candón ${ }^{2}$ and P. Martínez-Galan ${ }^{3}$ \\ ${ }^{l}$ Enagás S. A., Madrid, Spain \\ ${ }^{2}$ Department of Industrial Management, School of Engineering, University of Seville, Seville, Spain \\ ${ }^{3}$ Ingeman, Association for the Development of Maintenance Engineering, Seville, Spain \\ * Corresponding author
}

\begin{abstract}
During many years, asset management methodologies used in industry were focused on knowing and analysing the operational control of the daily work and the impact of the maintenance on the availability. Later, the costs turn into the priority, and strategies were focused on assessing a longer lifecycle and optimizing processes and contracts. Finally, recent normative have included concepts as "knowing and managing the risks" and the target is to prioritize the maintenance tasks to the critical assets. However, taking a balanced asset management model for the operational environment, quite a lot of facilities of Oil\&Gas sector are reaching the end of their initially estimated lifecycle. New challenges are related to extend the life of the main items of the facilities or at least, to find the optimal replacement moment that guarantees that the total expenditure (TOTEX) is being optimized.
\end{abstract}

Asset Health Index (AHI) methodology considers a theoretical lifecycle of an item, in which depending on the proximity to the end of the useful life, the probability of failure increases. But taking this theoretical lifecycle as a base, different operation location factors or operation and maintenance $(\mathrm{O} \& \mathrm{M})$ aspects can modify this period. All these factors can be quantified and permit us to calculate a new theoretical profile.

This paper is case study based on the theoretical procedure and methodology proposed in previous literature (i.e. De la Fuente, Candon et al., 2018) to assess the impact of future failure probabilities of assets on lifecycle cost. The paper shows the impact of the AHI into a profitability calculation. AHI has enabled to compare future alternative cost profiles and assess the impact in the failure probability of the item. As a result, we have been able to change the maintenance strategy and optimise the TOTEX of an industrial equipment.

\section{Introduction}

The target of the paper is to develop a case study assessing the impact of the operation and maintenance in the lifecycle of and asset, and consequently, in the maintenance strategy. To develop it, it is going to be assessed the profitability of the investment in a replacement asset process. Traditional profitability analysis takes into account standard operational expenditures (OPEX) and capital expenditures (CAPEX) concepts. However, when these studies are made for long term investments or for long time periods, the evolution of these costs are simplified to constant values over time.

Some concepts are easy to calculate because they have a lineal or non-variable evolution. If the asset technology is well known, electricity consumption or $\mathrm{CO} 2$ emission is a direct calculation. On the other hand, costs derived from the ageing of the assets as corrective maintenance are not easy to calculate and the methodology proposed supports in this aspect.

AHI provides an objective technical methodology to estimate the lifecycle bend and, in consequence, maintenance cost profiles in the future. This estimation enable us to use reliability index as availability in the investment study. CAPEX and OPEX have been traditionally used separately because were focused on specific targets; CAPEX for making the best investment, and OPEX for reaching operational efficiency. However, the methodology proposed is centred on TOTEX and look for the effectiveness of the asset management in long term results.

\section{Scope}

\subsection{Definition}

An Underground Storage of Natural Gas is used to store Natural Gas (NG) in low consumption periods (e.g. summer) and be able to use it in consumption peaks (e.g. winter). In the extraction process, NG flows mixed with water and other condensed products which are taken from the ground. To avoid mixing these products with the Gas Transport Grid, it is necessary to cool the gas. Water and impurities get condensed and can be eliminated. After that, NG get the right levels of water and hydrocarbons required by the law. 
Figure 1 Basic system diagram

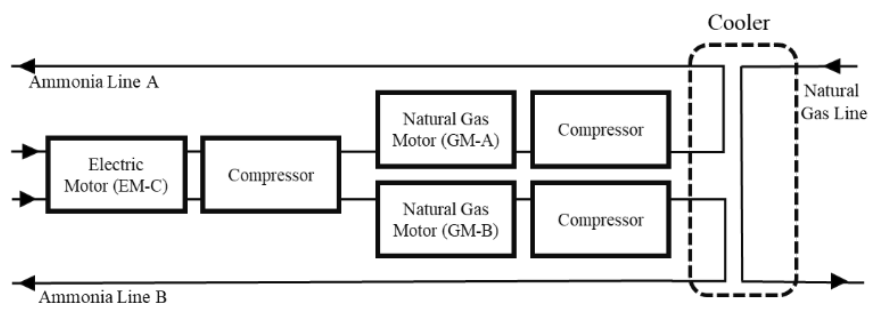

NG is cooled by two refrigeration lines whose refrigerant fluid is ammonia. This fluid must be compressed to maintain the heat exchange with NG. Three compressors are used for this process. These compressors are actuated for three motors of different technologies. Two NG motors used for compressors of line A and Line B, and a third electric compressor that can operate for both lines. The basic system diagram is shown in Figure 1.

As a result of the experience of the staff of the facility operating and maintaining the motors, it is proposed to change one of the $\mathrm{NG}$ motors for an electric one. It will avoid the $\mathrm{CO} 2$ emitted in the NG combustion and will optimise OPEX during the lifecycle of the item.

The target of the paper is to calculate the profitability analysis of the change, assessing the impact of the Health Index of the motors in the operation and maintenance costs. This methodology allows to estimate the impact of the ageing of an asset during the lifecycle.

\subsection{Operation scenarios}

According to the configuration of the system, electric compressor (EM-C) was used just as a backup of the NG ones.

As a result of the benefits of using the electrical motor the last year, the operating process time was divided at $50 \%$ for the electrical one and $50 \%$ for NG ones ( $25 \%$ for each one) as shown in Figure 2.

Figure 2 Current Operational mode

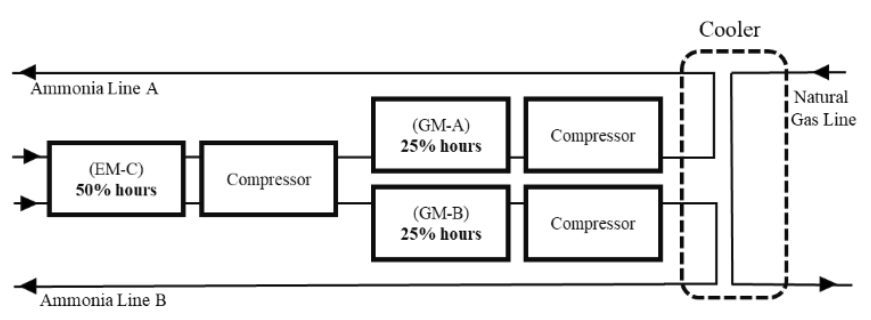

To maximize the benefits of the investment, the calculation is not only going to be based on the change of technology (GMA for EM-D) but on the change of the operational mode. The scenario proposed uses electrical motors as main equipment, letting the NG one as backup. It implies that actual EM-C will work $50 \%$ of the time, and preferably on line B. On the other hand, the new EM-D will be used the other $50 \%$ of the time, and can only work on line A. The new scenario is shown on Figure 3.

Figure 3 Proposal of new operational mode

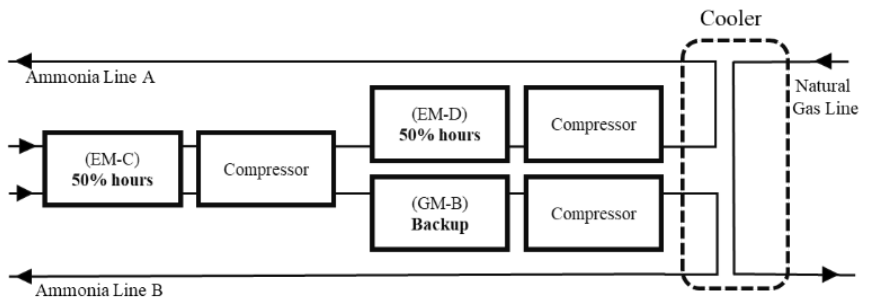

This proposal has several benefits that are going to have impact in the payback of the investment:

- Improving the energy efficiency; electrical motors has better efficiency rates during the operation so it is assumed to be an optimised use of energy.

- Decreasing CO2 emissions; avoiding the use of NG as energy for the NG motors can decrease significantly emissions of gases derived of combustion process.

- Increasing reliability of the facility; failure rates of electric motors are significantly lower than NG ones. This factor increases the availability level of the facility.

- Optimising maintenance costs; electric motors does not require overhauls, so the scheduled availability increases against $\mathrm{NG}$ motors.

- Decrease the criticality of the asset; according to the criticality analysis, (Crespo et al. 2016), (Serra, Crespo \& Sola 2018) NG Motors are more critical because of the environmental care impact. The change of technology decrease the criticality of the asset, and consequently provides the facility more flexibility in maintenance plans optimising processes.

\section{Asset Health Index Calculation}

AHI represents a practical methodology to quantify the general health of a complex asset. (De la Fuente, Gonzalez-Prida et al. 2018). The methodology is used to provide a mathematical base for supporting maintenance and replacement strategies. The index represent the asset conditioned based on a semi quantitative assessment of the factors that impact in the lifecycle of an item. With the assessment of the impact of the factors, we can use the results of operational observations, field inspections and laboratory tests, to simulate the lifecycle of an asset (Naderian et al. 2008). This estimation must help to know the future condition, and consequently the costs derived from the operation and maintenance.

In this case, the methodology is going to be applied in the $\mathrm{NG}$ motor (GM-A). It is supposed that the electrical one is a new asset and the wear and tear during the period of the analysis is 
not going to be relevant, so is not going to have impact into the global maintenance costs.

\subsection{Background}

$\mathrm{AHI}$ is used as is proposed by the UK DNO Common Network Asset Indices Methodology (UK DNO, 2017). AHI is considered as a dimensionless number between 0.5 (which corresponds to its status or condition as new equipment) and the value of 10 (corresponding to the condition of the equipment at the end of its useful life). The behaviour pattern of the AHI, is supposed to be exponential along the age of the asset. The Figure 4 shows the different five sections into which the health index of the asset is divided.

Figure 4 Asset Health Index Banding

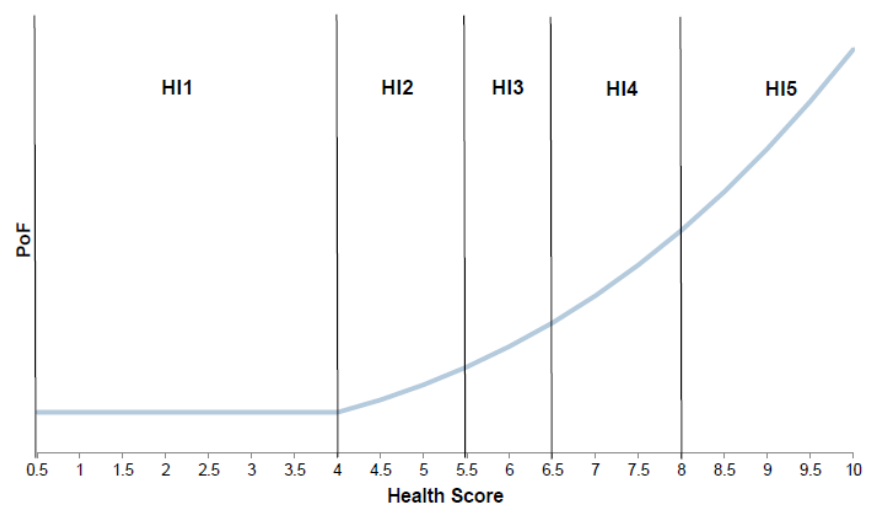

For every range, a specific behavior of the item is expected. The HI1 range comprised $0.5 \leq \mathrm{AHI} \leq 4$ values; for which the behavior of the equipment is assumed to resemble as new equipment. The HI2 range considers AHI values within the interval $4<\mathrm{AHI} \leq 6$ and corresponds to the period of time when the first signs of deterioration begin to appear in the equipment. In this range, the value corresponding to $\mathrm{AHI}=5.5$, is assumed to be the health index value equivalent to the normal life expected for the equipment category. From this point, three intervals are considered in the methodology: HI3, HI4 and HI5 as the AHI exceeds the values of 6,7 and 8 respectively. The methodology assumes that exceeded the value of $\mathrm{AHI}=8$, the equipment is at the end of its useful life.

\subsection{Procedure}

The methodology followed in this paper is based on a procedure consisting in five consecutive steps (De la Fuente, Candón et al. 2018). It has been taken as reference because is a specific adaptation of the standard methodology to Oil and Gas equipment. Taking the theoretical estimated normal life based on the provider information and associate with a specific equipment category, several factors update this expected life. Every aspect related with the asset condition is taken into account and used in the methodology. This procedure is presented in Figure 5.
Figure 5 AHI calculation procedure

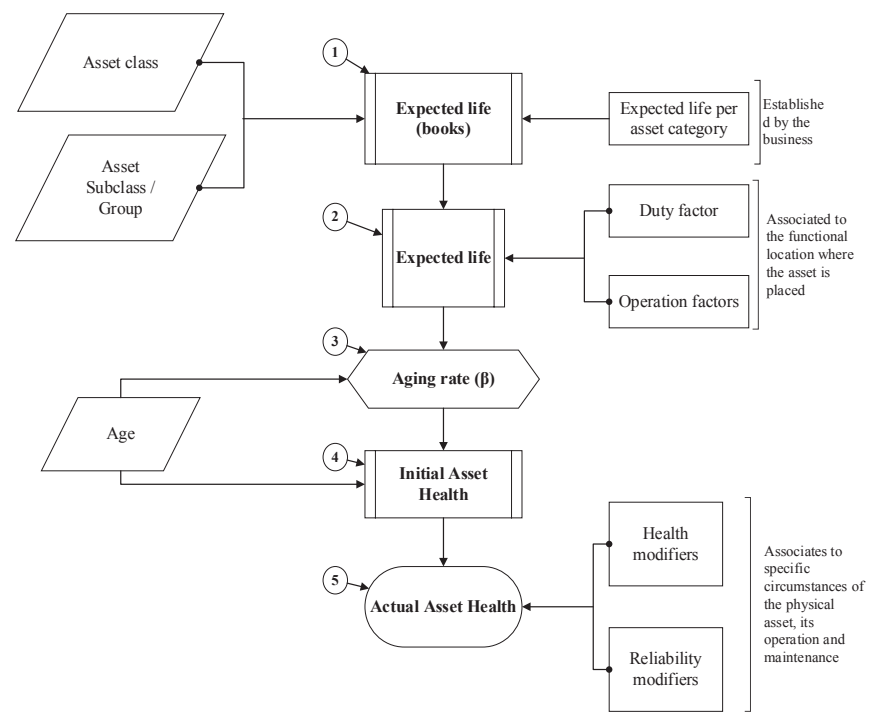

Using the theoretical procedure proposed (De la Fuente, Candón et al. 2018), the practical application is going to be explained with the case study of NG motor (GM-A) following the five steps define previously.

3.2.1 Asset selection and category definition: In this first step, the identification of the asset and all the information regarding its functional location is addressed. According to ISO 14224 the asset is included in rotating equipment category and the equipment class is known as "electric motors".

3.2.2 Evaluation of the impact of location and load factors: Once all the information in the previous point has been compiled, the location and loading factors are evaluated. This step will quantify the impact of the specific place of the asset, and the load conditions derived of it, into the expected life.

To calculate location factor $\left(F_{L T}\right)$, reference standards as DNO common network asset indices methodology proposes collections of factors, but these must be adapted to the type of facility and operational process. Location factors proposed for Underground Gas Storage are defined in Table 1, Table 2 and Table 3. The range and the value of the factors have been defined based on the experience and knowledge of the staff of the facility. The range that applies for GM-A is marked in grey.

Table 1 Location Factor; Distance to coast

\begin{tabular}{ll}
\hline Distance to coast $(\mathrm{km})$ & Factor Value \\
\hline $0 \mathrm{Km}-1 \mathrm{Km}$ & 1 \\
$1 \mathrm{Km}-5 \mathrm{Km}$ & 1.05 \\
$5 \mathrm{Km}-10 \mathrm{Km}$ & 1.1 \\
$10 \mathrm{Km}-20 \mathrm{Km}$ & 1.15 \\
$>20 \mathrm{Km}$ & 1.2 \\
\hline
\end{tabular}


Table 2 Location Factor; Outside Temperature

\begin{tabular}{ll}
\hline Temperature $\left({ }^{\circ} \mathrm{C}\right)$ & Factor Value \\
\hline $0^{\circ} \mathrm{C}-10{ }^{\circ} \mathrm{C}$ & 1 \\
$10{ }^{\circ} \mathrm{C}-20^{\circ} \mathrm{C}$ & 1.1 \\
$20{ }^{\circ} \mathrm{C}-30{ }^{\circ} \mathrm{C}$ & 1.2 \\
$>30{ }^{\circ} \mathrm{C}$ & 1.3 \\
\hline
\end{tabular}

Table 3 Location Factor; Height above sea level

\begin{tabular}{ll}
\hline Height $(\mathrm{m})$ & Factor Value \\
\hline $0-500$ & 1 \\
$500-1000$ & 1.1 \\
$1000-2000$ & 1.2 \\
$>2000$ & 1.3 \\
\hline
\end{tabular}

If there are several parameters that impacts in location factor calculation, the methodology defines that

$F_{L T}=\max \left(F_{L T 1}, F_{L T 2}, F_{L T X}\right)$

In this case, the first location factor $\left(F_{L T 1}\right)$ is distance to coast and the facility is off-shore, so the distance is $0 \mathrm{~km}$ and the factor value is 1 . The second factor $\left(F_{L T 2}\right)$ is outside temperature. The average value is $21^{\circ} \mathrm{C}$ throughout the year so the factor value according to the Table 2 is 1.1 . Finally, the height above sea also conditioned the expected life of the asset. In this case the facility is at sea level and the factor value is 1 . As a consequence, the Location Factor is 1.1 as shown in equation 2 :

$F_{L T}=\max (1,1.1,1)$

To calculate load factor $\left(F_{L}\right)$ it is necessary to measure the load requested during operation in the specific location against the maximum admissible load measured during the start-up process of the equipment.

$F_{L}=\frac{\text { Load normal conditions }}{\text { Maximum admissible load }}$

After running test, the load measure for nominal conditions is $90 \%$ of maximum admissible. In this case, the load factor $\left(F_{L}\right)$ is 0,9 . According to the methodology we can now calculate a new estimate life as a result of the equation

Estimated life $=\frac{\text { Normal life }}{F_{T L} \times F_{L}}$

The normal life defined by the provider is 25000 hours. It is the operation time until the overhaul must be done. Consequently, is the expected life noted by the provider in which the failure rate is the standard one, so the AHI is under 5.5 .

According to the evaluation of the impact and the location, the estimated life is higher and is expected to be under the standard failure rate until 25253 operation hours.
3.2.3 Calculation of the aging rate: A fundamental hypothesis of the chosen methodology is that the aging of an asset has an exponential behaviour with respect to its age. This aging can be calculated through the parameter aging rate, and permit us to use this rate for express mathematically the behaviour of failure rate during the lifecycle.

The calculation is

$\beta=\frac{\ln \frac{{ }_{\text {HI new }}}{H_{\text {estimated life }}}}{\text { Estimated life }}$

Where:

$\beta=$ Aging rate

$H I_{\text {new }}=0.5$ Health index corresponding to a new asset;

$H_{\text {estimated life }}=5.5$ Health index corresponding to an asset arriving to its estimated life;

3.2.4 Obtaining the Initial Health Index: After calculating the aging rate, we are able to obtain the Initial Health Index. This new Index represents an adaptation of the theoretical provider expected life into a new real expected life condition by the specific installation place (defined by location factors) and with a specific load condition (defined by the load factor). As a result, we obtain a graphical result shown in Figure 6.

$H I_{i}=H I_{n e w} x e^{\beta t}$

Where:

$t=$ the current age of the asset (in units of time)

Figure 6 Initial Health Index

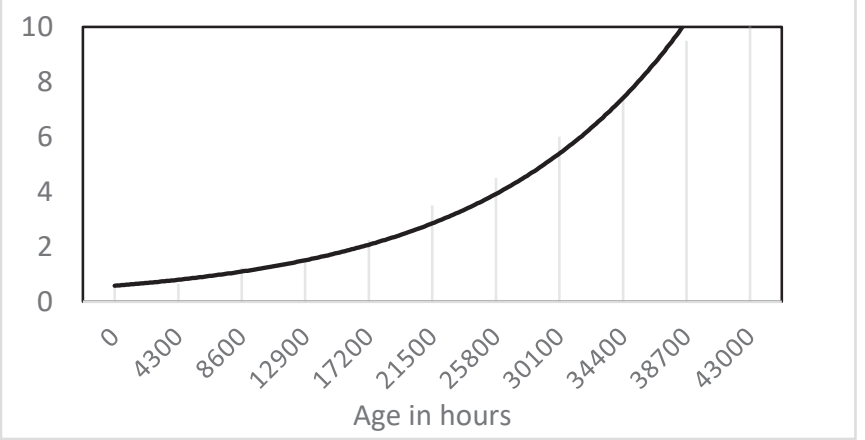

3.2.5 Calculation of the Real Health Index: In the last step, the aging of the asset can be increased or decreased by other modifiers that conditioned the operation and the maintenance. These factors are divided into three categories; reliability, load and healthy modifiers.

Reliability modifiers are shown in Table 4, Table 5 and Table 6 , and represents the results of the operation rules of the asset: 
Table 4 Reliability Modifier; Inactivity Operating Time

\begin{tabular}{cl}
\hline Inactivity (\%) & Modifier Value \\
\hline $0 \%-50 \%$ & 1 \\
$50 \%-75 \%$ & 1.05 \\
$75 \%-100 \%$ & 1.1 \\
\hline
\end{tabular}

Table 5 Reliability Modifier; Provider

\begin{tabular}{ll}
\hline Provider (average reliabity) & Modifier Value \\
\hline Under range average providers & 1.05 \\
Into range average providers & 1 \\
Upper range average providers & 1.05 \\
\hline
\end{tabular}

Table 6 Reliability Modifier; Overhauls number

\begin{tabular}{ll}
\hline Overhauls (number) & Modifier Value \\
\hline $1-3$ & 1 \\
$3-5$ & 1.05 \\
$>5$ & 1.1 \\
\hline
\end{tabular}

The healthy modifier is shown in Table 7 and quantify the impact of the specific operation parameter into the lifecycle of the asset. In this case the continuous start-ups of the machine:

Table 7 Health Modifier; Number of start-ups

\begin{tabular}{ll}
\hline Start-ups (number) & Modifier Value \\
\hline$<40$ & 1 \\
$40<\mathrm{x}<80$ & 1.2 \\
$80<\mathrm{x}<120$ & 1.4 \\
$>120$ & 1.6 \\
\hline
\end{tabular}

Finally, operating an asset out of load range can modify the expected life, and it must be represented by AHI. In this case it is represented in load modifier (Table 8).

Table 8 Load Modifier; Operating Load

\begin{tabular}{ll}
\hline Average Operation Load & Modifier Value \\
\hline Into the recommended range & 1 \\
$0 \%<\mathrm{X}<15 \%$ out of range & 1.3 \\
$15 \%<\mathrm{X}<30 \%$ out of range & 1.5 \\
\hline
\end{tabular}

The result of the process is shown in Figure 7 and includes the comparison between the initial health index and the current health index.
Figure $7 \mathrm{HI}$ initial vs HI real

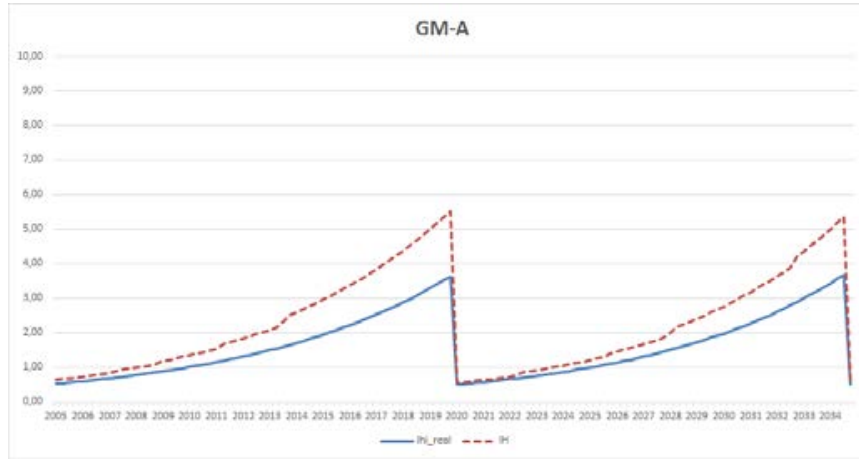

Having defined all the parameters, and calculated all the factors, we can finally obtain the Real Health $\operatorname{Index}\left(H I_{\mathrm{r}}\right)$. This value shows the most objective estimation of the age of an asset. It is calculated according to the next equation:

$H I_{r}=H I_{\text {new }} \frac{\beta t}{e^{M_{L}}} \times M_{H} \times M_{R}$

Where:

$M_{L}=$ Load Modifier

$M_{H}=$ Healthy Modifier

$M_{R}=$ Reliability Modifier

\subsection{AHI Results}

Depending on the design of the model, and the values of the modifiers, the Health Index, and consequently, the lifecycle, can be increased or decreased against the theoretical proposed by the provider. These results can be used as a base for management decisions (Table 9). Knowing the factors that impact in the health and calculating the HI, allow us to prevent premature aging and advance maintenance tasks. On the other hand, it also allows us to optimise operation and extending the life of the asset. With this information, we can adjust the maintenance plan and optimise the OPEX.

The results of the AHI calculated for motor (GM-A) shows that, because of the operation mode of the motor, its lifecycle is being shortened. According to the Health Index, the overhaul must be made in advance of at least two years. The Health Index in 2019 will reach 5.5, which is the moment when the failure rate can increase and consequently, impact into the reliability of the asset. This overhaul in advance, causes that in the period used for profitability calculation (15 years) two overhauls must be made instead of one. This change impacts directly in the economical result. 
Table 9 Load Modifier; Operating Load

\begin{tabular}{|c|c|c|c|}
\hline AHI & Condition & Expected lifetime & Requirements \\
\hline $0.5-4$ & Very good & $>5$ years & $\begin{array}{l}\text { Normal } \\
\text { maintenance }\end{array}$ \\
\hline $4-5.5$ & Good & $>4$ years & $\begin{array}{l}\text { Normal } \\
\text { maintenance }\end{array}$ \\
\hline $6-7$ & Fair & $2-3$ years & $\begin{array}{l}\text { Increase } \\
\text { diagnostic }\end{array}$ \\
\hline $7-8$ & Poor & $<2$ years & $\begin{array}{l}\text { Planning } \\
\text { replacing }\end{array}$ \\
\hline $8-10$ & Very poor & End of life & $\begin{array}{l}\text { Immediately } \\
\text { replace }\end{array}$ \\
\hline
\end{tabular}

\section{Profitability Calculation}

\subsection{Considerations}

To analyse the impact of the lifecycle maintenance cost of the motors into the profitability calculation, Internal Rate of Return (IRR) has been used as the main indicator to assess the benefits of the investment. To simplify the analysis and avoid unnecessary data, there have not been included all parameters that do not change between the scenarios that are going to be compared (replacing GM-A by EM-D or keeping it on GM-A).

4.1.1 Operational considerations: the operation parameters considered for the investment assessment are the energy consumption of the motors (NG for GM-A and GM-B or electricity for EM-C and EM-D) and the $\mathrm{CO} 2$ emitted in the NG combustion.

The operation scenario has been defined previously. To maximize the hypothetical benefits of the replacement, the proposal is not just to change the motors but to use electrical ones as the main equipment and leave the second NG motor (GM-B) as backup item. As a consequence, it is necessary to consider not just the energy savings of GM-A, but adding GMB. In the assessment we have consider a $90 \%$ of operational savings in GM-B. $10 \%$ of the operation time is maintained, considering the hypothetical backup operation of the motor, and the time used for periodical maintenance start-ups.

According to the previous consideration, $\mathrm{CO} 2$ emissions have been calculated estimating a total saving of GM-A emissions and a $90 \%$ of GM-B emissions.

4.1.2 Maintenance considerations: maintenance costs have been simplified into two concepts to simplify the assessment. Firstly, the general maintenance costs which includes periodical preventive maintenance and standard corrective maintenance (derived from the average failure rate). Based on AHI value, asset condition is supposed to be under 5.5, so corrective standard costs are fixed during the lifecycle. Secondly, the overhaul, which includes the major maintenance if it is required. In this case, this overhaul is just necessary for NG motors, and this factor is going to be critical in the calculation of profitability. Overtaking or delaying overhauls has a direct impact in the costs of the lifecycle.
4.1.3 Price considerations: To complete the analysis, it is necessary to take parameter prices as reference. All prices has been estimated with the recommendation of the specifics specialist departments of the company. However, for the business profitability calculation, parameters as $\mathrm{CO} 2$ ton or electricity has very variable prices and the margin of uncertainty is important. In this case, for the theoretical demonstration of the impact in the lifecycle, these prices have been considered fixed. The price used for electricity is $0,07 € / \mathrm{kWh}$ and for $\mathrm{CO} 2$ is $9,55 € /$ Ton. The IRR calculation requires also use specific economical parameters. The three economic factors considered have been; the discount rate $(25 \%)$, the increase of consumer price index $(2 \%)$ and the investment amortization period (15 years)

4.1.4 Investment considerations: To complete the comparison of the changing of the motor, it is necessary to include the costs needed for the installation of the new asset. In this concept are included all the costs; the asset, works necessaries for the installation, facility adaptation to new asset, engineering work hours, disassembly old equipment and control system modification. The value or these costs is $340 \mathrm{k} €$.

\subsection{Calculation of Internal Rate of Return}

To approve investment proposals, companies requires a clear profitability value. The key performance indicator to assess this viability is the Internal Rate of Return. The value required depends on the company. In most cases, no investment is approved with values lower than 6\% (a standard value of the Return Rate just for investing in the bank). The higher the IRR, the greater the probability the investment was approved.

To analyse the IRR, a standard spreadsheet has been used. Costs savings derived from the replacement of NG motor has been considered with positive value. In Table 10 are detailed direct costs of operation and maintenance of GM-A which are going to be eliminated because of the replacement:

Table 10 Cost Savings; GM-A

\begin{tabular}{lccl}
\hline Concept & Asset & Value $(\mathrm{k} €)$ & Periodicity \\
\hline Overhaul & GM-A & 140 & $25.000 \mathrm{~h}$ \\
Maintenance & GM-A & 10 & Annual \\
Natural Gas & GM-A & 30 & Annual \\
CO2 emissions & GM-A & 1,83 & Annual \\
\hline
\end{tabular}

As it has been explained previously, it is also considered the savings derived from the operational change mode. It implies a $90 \%$ reduction of annual costs, and not taking into account a hypothetical overhaul of GM-B, because the operational hours will not reach 25.000 hours during the investment calculation. The detail is shown in Table 11. 
Table 11 Cost Savings; GM-B

\begin{tabular}{lccl}
\hline Concept & Asset & Value $(\mathrm{k} €)$ & Periodicity \\
\hline Overhaul & GM-B & 140 & Not used \\
Maintenance & GM-B & 9 & Annual \\
Natural Gas & GM-B & 27 & Annual \\
CO2 emissions & GM-B & 1,65 & Annual \\
\hline
\end{tabular}

New costs derived from the installation of the EM-D, has been considered in the spreadsheet with negative value and are detailed in Table 12.

\section{Table 12 Cost Increase}

\begin{tabular}{lccl}
\hline Concept & Asset & Value $(\mathrm{k} €)$ & Periodicity \\
\hline Overhaul EM & EM-D & 0 & Not applied \\
Maintenance & EM-D & 4 & Annual \\
Electricity & EM-D & 50 & Annual \\
\hline
\end{tabular}

4.2.1 Calculation without AHI: If the assessment was done without including AHI concept, the calculation was normal. The only singular point would be to estimate when is going to be the overhaul done. Assuming annual operation hours defined in the base case, there will be necessary just one overhaul during the lifecycle of the investment (15 years) which might be done in the fifth year of the cycle (according to the actual situation of the asset). Using standard data into the spreadsheet and with the considerations defined along the paper, the IRR will be $7.54 \%$. Figure 8 represents a simplified image of the spreadsheet. It includes the first year (moment of the hypothetical investment), the second year (that is the example for the rest the years) and the year where the overhaul is going to be executed.

Figure 8 IRR spreadsheet without HI

\begin{tabular}{|c|c|c|c|c|c|c|}
\hline Concepts & Euros & Frequency & year 1 & year 2 & year 6 & year 16 \\
\hline Overhaul GM & 140,00 & $25000 \mathrm{~h}$ & & & 140,00 & \\
\hline Maintenance GM-A & 10,00 & anual & & 10,00 & 10,82 & 13,19 \\
\hline Maintenance GM-B & 9,00 & anual [ & & 9,00 & 9,74 & 11,88 \\
\hline Maintenance EM & $-4,00$ & anual & & $-4,00$ & $-4,33$ & $-5,28$ \\
\hline Operation Natural Gas GM-A & 30,00 & anual & & 30,00 & 32,47 & 39,58 \\
\hline Operation Natural Gas GM-B & 27,00 & anual & & 27,00 & 29,23 & 35,63 \\
\hline Electric consumption EM-D & $-50,00$ & anual & & $-50,00$ & $-54,12$ & $-65,97$ \\
\hline $\mathrm{CO} 2$ Ton GM-A & 1,83 & anual & & 3,83 & 4,14 & 5,05 \\
\hline $\mathrm{CO} 2$ Ton GM-B & 1,65 & anual] & & 3,45 & 3,73 & 4,55 \\
\hline EBITDA & & & & 29,28 & 171,69 & 38,63 \\
\hline Amortization & & & & $-22,67$ & $-22,67$ & $-22,67$ \\
\hline EBIT & & & & 6,61 & 149,02 & 15,96 \\
\hline EBIT * (1-t) & & & & 4,96 & 111,77 & 11,97 \\
\hline Amortization & & & & 22,67 & 22,67 & 22,67 \\
\hline Total Investment & \multicolumn{6}{|c|}{$-340,00$} \\
\hline Cash Flow & \multirow{2}{*}{\multicolumn{6}{|c|}{$\begin{array}{r}-340,00 \\
-340,00\end{array}$}} \\
\hline Cash Flow (sin amortización) & & & & & & \\
\hline IRR & $\mathbf{7 , 5 4 \%}$ & & & & & \\
\hline
\end{tabular}

4.2.2 Calculation with AHI: When the assessment is done taking into account AHI, some key aspects change significantly. The curve that represents $H I_{r}$ (Figure 7) demonstrate that the asset condition is worse than expected for current working hours. The factor that have more influence in the wear and tear is the healthy modifier. It results in major maintenance being advanced four years. Even a second overhaul must be done into the analysis period. With these data included in the spreadsheet (Figure 9), IRR changes significantly, increasing the value until $10,56 \%$.

Figure 9 IRR spreadsheet with HI

\begin{tabular}{|c|c|c|c|c|c|c|}
\hline Concepts & Euros & Frequency & year 1 & year 2 & year 3 & year 16 \\
\hline Overhaul GM & 140,00 & $25000 \mathrm{~h}$ & & 140,00 & & 140,00 \\
\hline Maintenance GM-A & 10,00 & anual & & 10,00 & 10,20 & 13,19 \\
\hline Maintenance GM-B & 9,00 & anual & & 9,00 & 9,18 & 11,88 \\
\hline Maintenance EM & $-4,00$ & anual & & $-4,00$ & $-4,08$ & $-5,28$ \\
\hline Operation Natural Gas GM-A & 30,00 & anual & & 30,00 & 30,60 & 39,58 \\
\hline Operation Natural Gas GM-B & 27,00 & anual & & 27,00 & 27,54 & 35,63 \\
\hline Electric consumption EM-D & $-50,00$ & anual & & $-50,00$ & $-51,00$ & $-65,97$ \\
\hline $\mathrm{CO} 2$ Ton GM-A & 0,00 & anual & & 3,83 & 3,91 & 5,05 \\
\hline $\mathrm{CO} 2$ Ton GM-B & 0,00 & anual & & 3,45 & 3,52 & 4,55 \\
\hline EBITDA & & & & 169,28 & 29,86 & 178,63 \\
\hline Amortization & & & & $-22,67$ & $-22,67$ & $-22,67$ \\
\hline EBIT & & & & 146,61 & 7,19 & 155,96 \\
\hline EBIT * (1-t) & & & & 109,96 & 5,40 & 116,97 \\
\hline Amortization & & & & 22,67 & 22,67 & 22,67 \\
\hline Total Investment & & & $-340,0$ & & & \\
\hline Cash Flow & & & $-340,0$ & 132,62 & 28,06 & 139,64 \\
\hline Cash Flow (sin amortización) & & & $-340,0$ & 132,62 & 28,06 & 139,64 \\
\hline
\end{tabular}

\section{Conclusion}

The use of the methodology of AHI for the profitability calculation has had a deep impact. It has conditioned significantly the maintenance strategy during the lifecycle of the investment.

It is not only the final $4 \%$ of difference in the IRR between the calculations without $\mathrm{AHI}$ against the one with $\mathrm{AHI}$. The reason that make the investment more realistic, is the knowledge of the real status of the asset. This knowledge enables us to turn a subjective assessment of asset condition into a mathematical calculation

The application of the methodology allows us to know that the operational mode of the Gas Motor has decreased significantly its lifecycle. Assuming the information given by the provider, it could be possible to reach 25.000 operation hours. And this scenario is not necessaryly wrong. The AHI allow us to determine the risk that it is being assumed by waiting until the overhaul. Or even if it is possible, to advance this major maintenance, ensuring that the asset condition is good enough.

In a business profitability assessment, non-lineal costs are the values most difficult to estimate. Especially when the asset is reaching the end of the useful life, it is difficult to quantify the increase of the costs derived from the wear and tear.

Finally, is also important to remark that one of the most valuable aspects of a semi quantitative methodology, is the knowledge management. In this paper all the parameters of the procedure (modifiers, factors...) are assumed. But the process of obtaining the necessary agreements by the specialist, implies to sharing the knowledge, and recording deliverables. For companies with specialists with more than 40 years, and consequently, close to retire, it is essential to keep the knowledge of these staff and ensure that their experience is going to be maintained in the company. 


\section{References}

De la Fuente, A; Candón, E; Martínez-Galán, P; Crespo, A; Sola, A and Moreu, P. (2018). Asset health index method for a process pumps fleet. Industria química, ISSN 2340-2113, $\mathrm{N}^{\circ}$. 57, 2018 (Special ACHEMA 2018), Pp. 38-43.

UK DNO Common Network Asset Indices Methodology. (2017). Health and Criticality. Version 1.1. January 30th.

Crespo Márquez, Adolfo; Moreu de Leon, Pedro; Sola Rosique, Antonio; Gómez Fernández, Juan Francisco. Criticality Analysis for Maintenance Purposes: A Study for Complex In-service Engineering Assets. En: Quality and Reliability Engineering International. 2016. Núm. 32. Pag. 519-533.

De La Fuente, A.; González-Prida, V.; Guillén, A.; Crespo, A.; Sola, A.; Gómez, J.; Moreu, P. (2018). Strategic view of an Assets Health Index for making long-term decisions in different industries. Safety and Reliability - Safe Societies in a Changing World. Haugen et al. (Eds). (C) 2018 Taylor \& Francis Group, London, ISBN 978-0-8153-8682-7. Pp 1151-1156

ISO 14224, Petroleum, petrochemical and natural gas industries - Collection and exchange of reliability and maintenance data for equipment.

Naderian, A., S. Cress, R. Piercy, F. Wang, and J. Service. 2008. "An Approach to Determine the Health Index of Power Transformers." Conference Record of the 2008 IEEE International Symposium on Electrical Insulation (July 2008):192-96.

Serra Parajes, J.; Crespo Márquez, A; and Sola Rosique, A. "Criticality analysis for preventive maintenance optimization purposes in gas network infrastructures," Proc. Inst. Mech. Eng. Part O J. Risk Reliab., 2018.Ges 